\title{
Projetos integradores no Ensino de Música: o caso da Prova de Aptidão Profissional
}

\section{Integrating projects in Music Education: the case of the Professional Aptitude \\ Test}

\author{
Luísa Orvalho*, Catarina Nunes**, \\ *Católica Porto, **Esproarte
}

\begin{abstract}
Resumo
Partindo da convicção de que a gestão do currículo em plena articulação com o projeto educativo da escola, a criação de estratégias e metodologias de ensino viáveis, são elementos eficazes e catalisadores da promoção da qualidade do ensino e da aprendizagem, pretende-se partilhar alguns dos projetos integradores desenvolvidos no âmbito da Prova de Aptidão Profissional da ESPROARTE - Escola Profissional de Arte de Mirandela que, por viabilizarem aos alunos, aspirantes a músicos profissionais, um modo de aprender baseado na experimentação e na integração de várias áreas do saber, muito têm contribuído para o desenvolvimento de competências e habilidades para um bom desempenho académico e profissional.

Palavras-Chave: [ensino profissional e artístico, projetos integradores, prova de aptidão profissional]
\end{abstract}

\begin{abstract}
Starting from the conviction that the management of the curriculum in full coordination with the educational project of the school, the creation of viable strategies and teaching methodologies, are effective elements, as well as enablers of the promotion of the quality of teaching and learning, it is intended to share some of the projects developed under the Professional Aptitude Test ESPROARTE- Professional school for Art of Mirandela that, by enabling students, aspiring professional musicians, a way to learn based on experimentation and integration of various areas of knowledge, have contributed to the development of competencies and skills for academic and professional performance.

Keywords: [professional and artistic education, integrating projects, professional aptitude test]
\end{abstract}

\section{Ensinar e aprender no século XXI: que desafios?}

São muitas as mudanças drásticas que caracterizam a sociedade atual e que têm, consequentemente, implicações profundas para o ofício do professor e das escolas. Contrariamente a outras gerações passadas que podiam dar-se ao luxo de preparar as suas crianças e jovens para integrarem um panorama social e cultural muito semelhante ao seu, atualmente observa-se uma rutura drástica entre a geração atual e a anterior, pois o futuro deixou de ser uma projeção imediata do passado
(Equipa Internacional de Países Participantes do Programa PETRA II, Ação I, 1995). Não obstante o facto de a criação de ambientes de aprendizagem ser a principal preocupação e dever das instituições e dos indivíduos, a grande maioria dos professores ativos no sistema educativo atual

formou as suas imagens de aprendizagem em escolas do modelo tipo fábrica (...) [em que] a escola oferece os conhecimentos necessários para a vida inteira, e a tarefa do aluno consistia em aprender e aplicar fielmente esses conhecimentos; neste contextos o papel do professor era muito claro; o professor possuía a informação, que transmitia ao aluno, através dos meios que tinha à sua disposição. Os alunos que conseguiam reproduzir e repetir essa informação eram considerados bem sucedidos; os que não conseguiam eram tidos como uns falhados. Era tudo tão simples! Agora tudo mudou, mudou radicalmente! (EIPPP II, Ação I, 1995, pp.28)

Esta conjuntura trouxe consigo uma crise profunda nas instituições de ensino que, de uma forma geral, tem revelado dificuldades em acompanhar essas mudanças, mantendo-se alicerçadas nas práticas metodológicas ditas "tradicionais" e assentes na ideia ultrapassada de transmissão de conhecimentos. Neste sentido, um dos primeiros obstáculos apontado enquanto impedimento à atualização da escola do século XXI é a fragmentação do conhecimento apresentado com base numa matriz curricular organizada por disciplinas fechadas para si e que acabam por dificultar ao aluno a conquista de uma visão contextualizada dos vários elementos que constituem o universo da aprendizagem, bem como a construção de um pensamento crítico da realidade (Morin, 2001).

Aliada a estas conceções, surge a necessidade de refletir sobre as metodologias utilizadas na escola de forma a procurar novas formas que promovam a integração de saberes e potenciem aos alunos uma aprendizagem enriquecida (Nóvoa, 2009). Neste sentido, a alternativa mais viável para a conquista da integração de saberes passa pelo trabalho conjunto entre os professores das várias disciplinas, pelo cultivo do 
diálogo entre alunos e docentes, bem como por um entendimento da educação enquanto prática social que se rege a par de uma pluralidade de áreas do conhecimento, ou seja através interdisciplinaridade promovida a partir do recurso a projetos integradores.

\section{Projetos integradores}

A inclusão de projetos integrados no currículo não é uma ideia nova na domínio da educação. No princípio do século XX John Dewey criou a pedagogia de projeto, um princípio pedagógico que teve como objetivo fundamental potenciar a aprendizagem baseada na realização de atividades experimentais devidamente articuladas com os conteúdos ensinados, de forma a que o aluno assumisse uma postura ativa durante todo o processo e que privilegiasse uma pedagogia participativa ao invés da já esgotada pedagogia transmissiva. Carl Rogers (1961) propõe uma perspetiva humanista centrada na pessoa, onde o aluno é o protagonista ativo e o professor um facilitador na construção do seu conhecimento.

Contudo, a realidade social atual tem desafiado os professores a repensar as suas práticas pedagógicas de forma constante e sistemática, incentivando a adoção de uma postura reflexiva que privilegie a investigação, a pesquisa e estimule o espírito crítico e a criatividade. Neste sentido, emerge a adoção de práticas, metodologias e recursos de aprendizagem que se coadunem com as necessidades e exigências atuais, que sejam capazes de suplantar a transmissão e a reprodução de conteúdos assentes no cânone reducionista escutar escrever - ler - decorar - repetir, dando primazia a processos que privilegiem a investigação, a problematização, a argumentação, a produção, a criação, a projeção e a visão crítica (Behrens, 2006). A este propósito Edgar Morin (2001, p.15) alerta

(...) ensinam-nos a isolar os objetos, a separar as disciplinas, a dissociar os problemas, em vez de reunir e integrar. Obrigam-nos a reduzir o complexo ao simples, isto é, a separar o que está ligado; a decompor e não a recompor; a elimina tudo o que causa desordens ou contradições no nosso entendimento.

O mesmo autor entende ainda que a pedagogia de projeto propicia uma formação contextualizada e dinâmica, uma vez que pretende suscitar o empenho, procurar a motivação e o interesse, encorajar o aluno a orientar-se e a organizar-se de forma autónoma, a formular, inquirir, procurar, agir em grupo, produzir e a participar na avaliação do seu próprio trabalho. A metodologia de projetos é, portanto, encarada enquanto estratégia favorecedora da pesquisa da realidade e do trabalho ativo por parte dos alunos, uma vez que transpõe os limites curriculares, implica a realização de atividades práticas que se coadunam com os interesses dos alunos envolvidos, bem como potencia a pesquisa individual e em grupo, desenvolve a autonomia e privilegia a integração de saberes e experiências advindas de diferentes fontes, disciplinas e áreas, originando um produto final comum capaz de oferecer um melhor conhecimento dos alunos, dos professores e da realidade.
Neste contexto, o processo de ensino-aprendizagem é organizado num ambiente alicerçado na realidade do aluno e na resolução de problemas, de modo a que este consiga estabelecer conformidades entre o que está a aprender e o contexto do aluno, oferecendo-lhe ferramentas para pensar de forma autónoma, crítica e contemplando a criatividade em todas as etapas (Morin, 2009). Segundo Hernandez (1998) o projeto favorece a criação de estratégias de organização das informações e do conhecimento em torno de problemas ou hipóteses que facilitem aos alunos a transformação das informações provenientes de diferentes saberes disciplinares em conhecimento próprio. Logo, a metodologia de projetos intensifica a ampliação da visão inter e transdisciplinar, uma vez que assenta num processo metodológico de aprendizagem que envolve níveis de integração de informações, conhecimentos e saberes, permitindo uma compreensão mais complexa de um determinado contexto.

À luz destas premissas, pretende-se partilhar um conjunto de ações determinantes no processo de construção e de execução da Prova de Aptidão Profissional (PAP) realizada no âmbito do Curso de Instrumentista de Cordas e de Tecla e do Curso de Instrumentista de Sopros e Percussão, ambos no nível 4 de formação na ESPROARTE que, por primarem pela mobilização de saberes e de competências adquiridos ao longo do plano de formação do curso frequentado, muito têm contribuído para o sucesso escolar dos alunos envolvidos

\section{Prova de Aptidão Profissional: um projeto integrador de saberes}

Segundo a Portaria no 74-A/2013, de 15 de fevereiro, a Prova de Aptidão Profissional (PAP) consiste na apresentação e defesa, perante um júri, de um projeto realizado pelo aluno capaz de mobilizar saberes e competências adquiridos ao longo do plano de formação do curso frequentado. Trata-se, portanto, de um projeto pessoal, revestido de caráter de investigação aplicada e como tal deverá estar em concordância com os interesses do aluno, de forma a que se manifeste um instrumento de interiorização de aprendizagens e de valorização profissional.

Assumindo que a teoria e a prática da música são transversais, a constante procura de estratégias viáveis que permitam integrar o ensino e fazer com que cada um dos alunos vivencie, tão frequentemente quanto possível, situações fecundas de aprendizagem, é impreterível. Por esta razão, na ESPROARTE a PAP contempla quatro componentes distintas que são articuladas entre a área Técnica, Tecnológica e Artística e a área Científica: Recital de Instrumento, Prova de Música de Câmara, Prova de Orquestra e, finalmente, a execução de um Projeto Integrador desenvolvido em equipa e revestido de caráter de investigação aplicada, que permita a troca de experiências e resulte dos interesses dos alunos envolvidos, fator determinante para a validação desta prova enquanto um instrumento de interiorização de aprendizagens, bem como de valorização e de intervenção profissional. 
Tratando-se de um projeto integrador de saberes e competências adquiridas ao longo dos anos de formação, a PAP é constituída por três fases fundamentais que preveem um conjunto de tarefas devidamente faseadas:

Tabela 1.

Fases e tarefas compreendidas no processo da PAP

\begin{tabular}{|c|c|}
\hline Fase & Tarefas \\
\hline Conceção & 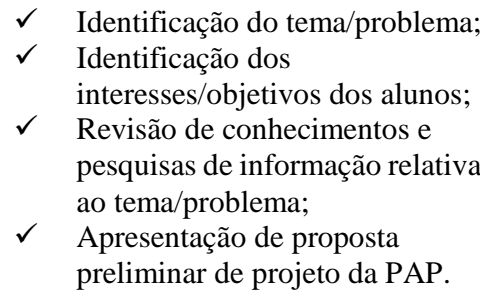 \\
\hline Desenvolvimento & $\begin{array}{ll}\checkmark & \begin{array}{l}\text { Desenho de tarefas } \\
\text { desenvolver; }\end{array} \\
\checkmark & \text { Recolha e tratamento de dados - } \\
\text { questionários, entrevistas, } & \text { observações, leituras. } \\
\checkmark & \begin{array}{l}\text { Preparação do projeto (possível } \\
\text { simulação); }\end{array} \\
\checkmark & \text { Elaboração de conclusões. }\end{array}$ \\
\hline $\begin{array}{c}\text { Autoavaliaçãa e } \\
\text { avaliação }\end{array}$ & $\begin{array}{l}\checkmark \quad \text { Redação de um relatório } \\
\text { constituinte do projeto; } \\
\checkmark \text { Apresentação do relatório e } \\
\text { defesa do projeto perante um } \\
\text { júri de avaliação. }\end{array}$ \\
\hline
\end{tabular}

Durante todo o processo os alunos são orientados pelos professores acompanhantes designados pela Direção Pedagógica, bem como pelos restantes professores do conselho de turma que são chamados a intervir na respetiva área vocacional sempre que se justifica.

Contudo, conscientes da relevância da associação a situações presentes no meio sociocultural e geográfico de cada aluno, bem como do incentivo à intervenção positiva quer no meio escolar quer na comunidade, a aposta centrou-se na criação de vários projetos integradores assentes numa lógica de compromisso e responsabilidade compartilhada e alicerçada numa cultura colaborativa entre a ESPROARTE e várias instituições e atores locais que, não obstante os domínios e as missões específicas de cada um, têm sido capazes de se aventurar num compromisso comum a todos. Neste contexto, destacam-se as intervenções dos alunos em grupos dedicados à divulgação da música tradicional portuguesa e coros amadores, na criação de conjuntos instrumentais com vista à realização de concertos, bem como na realização de diversas atividades no domínio da performance e da expressão musical noutras instituições de ensino e centros de acolhimento ocupacionais. A Universidade Sénior de Rotary, o Rancho Folclórico de Santiago, o Coro da Paróquia de Nossa Senhora da Encarnação e a Associação Portuguesa de Pais e Amigos do Cidadão Deficiente Mental (APPACDM), foram algumas das entidades locais onde os alunos realizaram as respetivas intervenções.

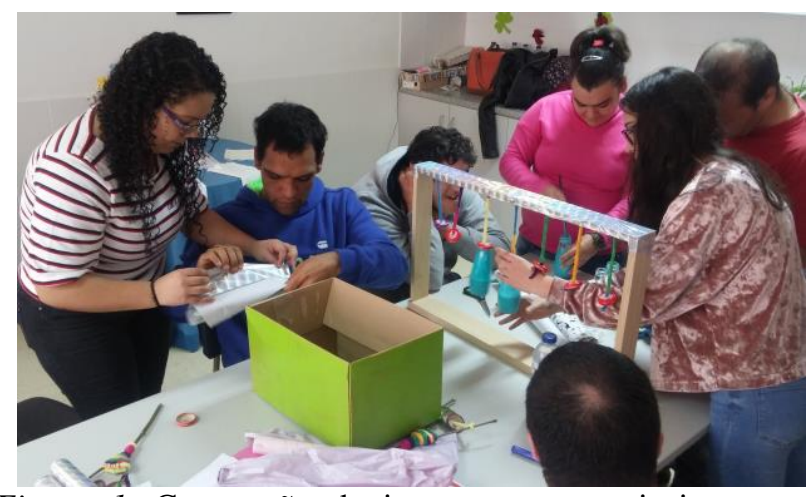

Figura 1. Construção de instrumentos musicais com recurso a materiais recicláveis junto dos utentes da APPACDM, em Mirandela.

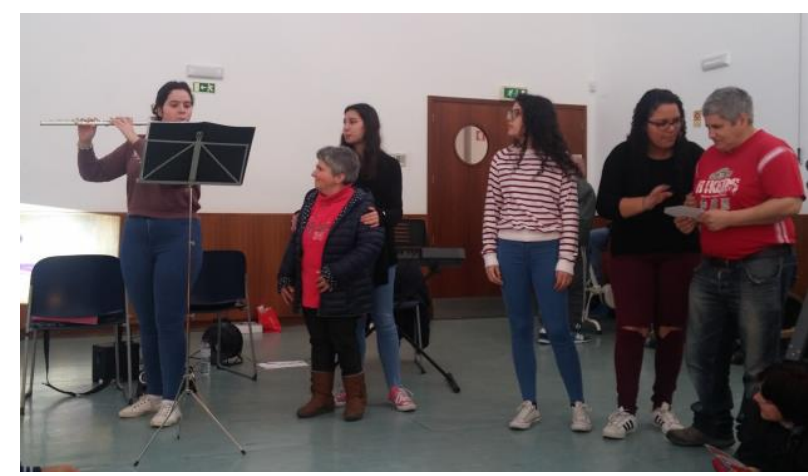

Figura 2. Sessão de expressão musical orientada pelos alunos da ESPROARTE junto dos utentes da APPACDM, em Mirandela.

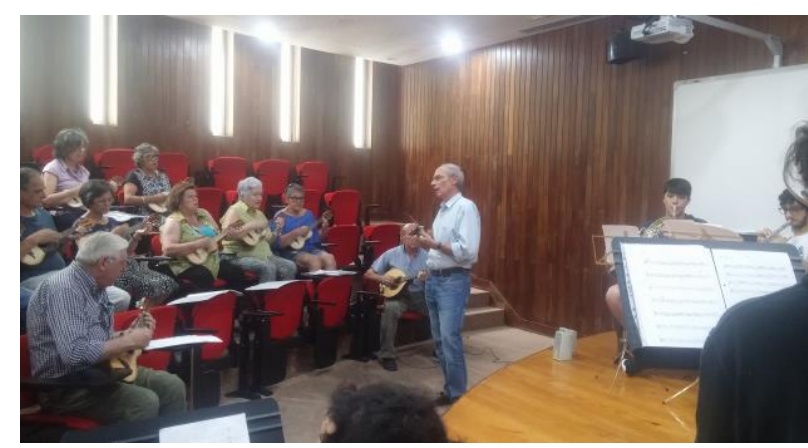

Figura 3. Ensaio de reportório tradicional com o Grupo de Cavaquinhos da Universidade Sénior de Rotary de Mirandela.

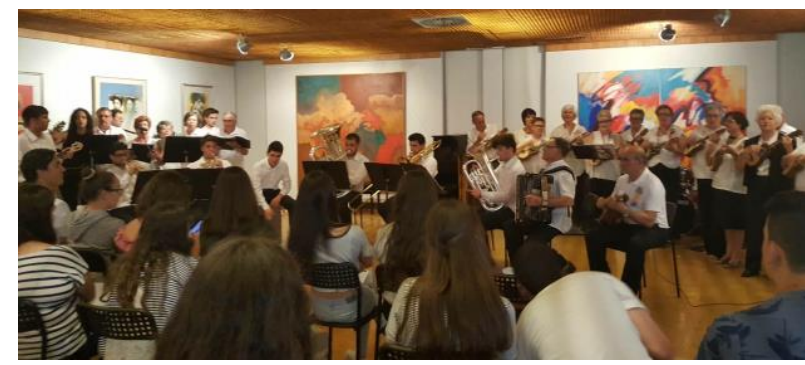

Figura 4. Concerto dos alunos da ESPROARTE e do Grupo de Cavaquinhos da Universidade Sénior de Rotary de Mirandela, no Museu Armindo Teixeira Lopes, em Mirandela. 


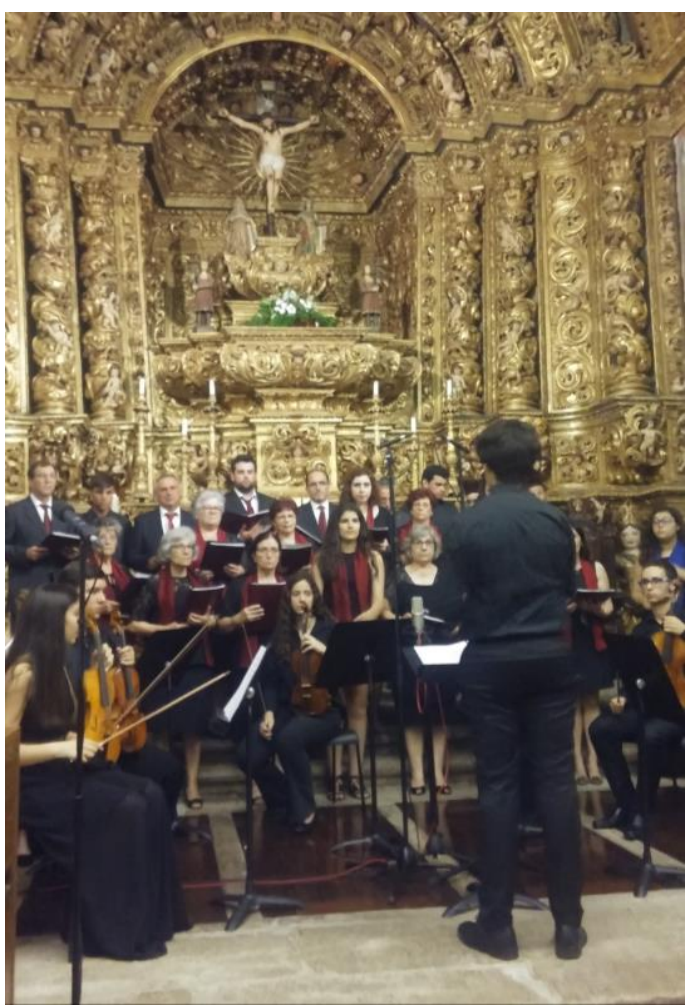

Figura 5. Concerto dos alunos da ESPROARTE com o Coro da Paróquia de Nossa Senhora da Encarnação, na Igreja da Misericórdia, em Mirandela.

Não obstante o facto de a criação destas parcerias contribuir diretamente para o desenvolvimento cultural e artístico da cidade, tem permitido acima de tudo o desejado envolvimento de toda a comunidade escolar na formação e educação dos nossos jovens, bem como tem vindo a possibilitar a apropriação efetiva dos conhecimentos, capacidades e atitudes que potenciam o desenvolvimento de competências-chave para a vida futura destes jovens. Os alunos aprendem fazendo, reconhecem a própria autoria naquilo que produzem, fator que os impulsiona a contextualizar conceitos já conhecidos e a descobrir outros que emergem durante o desenvolvimento do projeto. Nesta situação de aprendizagem, os nossos alunos são encorajados a selecionar informações significativas, tomar decisões, trabalhar em grupo, gerenciar confronto de ideias, desenvolver competências interpessoais para aprender de forma colaborativa com os seus pares. Os alunos têm oportunidade de refletir sistematicamente sobre as atividades que desenvolvem, sobre as decisões que tomam e consequentemente veem-se obrigados a agir de forma mais autónoma para solucionar um problema. A avaliação, por sua vez, é feita continuamente o que permite que os alunos se apercebam dos pontos fortes e dos aspetos melhorar e é gerado um produto final, cuja qualidade é conjuntamente avaliada. Para os alunos acostumados a uma escola mais tradicional, trabalhar por projetos significa uma transformação, na qual eles deixam de seguir ordens e passam a executar atividades de aprendizagem direcionadas por eles mesmos. Deixam de memorizar e repetir e passam a descobrir, integrar e apresentar. Deixam de ouvir e reagir e passam a comunicar e assumir responsabilidades. Passam da teoria à aplicação da teoria, deixam de depender do professor e assumem o poder final. Para os professores, os benefícios adicionais incluem a colaboração entre colegas, oportunidades de reforçar laços com os alunos e de se envolverem em processos de investigação-ação que potenciam o questionamento sistemático sobre a ação e que, consequentemente, podem ser um caminho para o desenvolvimento de competências, bem como para inovação na prática docente. $\mathrm{O}$ papel do professor deixa de ser aquele que ensina por meio da transmissão de informações para criar situações de aprendizagem, cujo foco incide sobre as relações que se estabelecem neste processo, cabendo ao professor realizar as mediações necessárias para que o aluno possa encontrar sentido naquilo que está a aprender, a partir das relações criadas nessas situações.

Embora constitua um desafio quer para os alunos, quer para os professores, a gestão flexível do currículo e a promoção de um modo de aprender focado na experimentação e na integração de várias áreas do saber, têm permitido que a PAP seja mais uma oportunidade para a formação de jovens autónomos, criativos e agentes ativos do próprio conhecimento, manifestamente capazes de interferir positivamente no seu contexto sociocultural.

\section{Referências}

Behrens, M. (2006). O paradigma da complexidade. Metodologia de Projetos, contratos didáticos e portefólios. Petrópolis: Vozes.

Equipa Internacional de Países Participantes do Programa Petra II, Ação II (1995).O Professor Aprendiz - criar o futuro. Porto: DES.

Hernandez, F. (1998). Transgressão e mudança na educação: os projetos de trabalho. Porto Alegre: Artmed.

Morin, E. (2001). A religação dos saberes: o desafio do século XXI. Rio de Janeiro: Bertrand.

Morin, E. (2009). A cabeça bem feita. Repensear a reforma. Reformar o pensamento. Rio de Janeiro: Bertrand.

Nóvoa, A. (2009). Educação 2021: para uma história do futuro. Revista Ibero-Americana. No 49 , jan-ab, pp. 181-199.

Rogers, C. (1961). Tornar-se Pessoa. São Paulo: Martins Fontes.

Portaria n. ${ }^{\text {7 }}$ 74-A/2013 de 15 de fevereiro do Ministério da Economia e do Emprego e da Educação e Ciência. Diário da República: 1. ${ }^{a}$ série - N. 33 (2013). Acedido a 30 de junho de 2017. [Disponível em www.dre.pt]. 